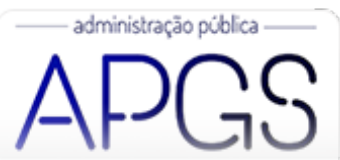

Administração Pública e Gestão Social ISSN: 2175-5787

apgs@ufv.br

Universidade Federal de Viçosa

Brasil

\title{
SER OU NÃO SER - EIS A GESTÃO: as emoções na prática gerencial
}

De Lucena Macedo, José Wilker; Barbosa da Silva, Anielson

SER OU NÃO SER - EIS A GESTÃO: as emoções na prática gerencial

Administração Pública e Gestão Social, vol. 14, núm. 1, 2022

Universidade Federal de Viçosa, Brasil

Disponible en: https://www.redalyc.org/articulo.oa?id=351569604005

\section{(c) $(1) \Theta \Theta$}

Esta obra está bajo una Licencia Creative Commons Atribución-NoComercial-SinDerivar 4.0 Internacional. 


\title{
SER OU NÃO SER — EIS A GESTÃO: as emoções na prática gerencial
}

\section{TO BE OR NOT TO BE - THAT IS THE MANAGEMENT: emotions in management practice ¿SER O NO SER? ESTO ES GESTIÓN: las emociones en la práctica directiva}

\author{
José Wilker De Lucena Macedo \\ Universidade Federal da Paraiba, Brasil \\ wilker.inss@gmail.com \\ Anielson Barbosa da Silva \\ Universidade Federal da Paraíba, Brasil \\ anielson@uol.com.br
}

\author{
Redalyc: https://www.redalyc.org/articulo.oa? \\ $\mathrm{id}=351569604005$
}

Recepción: 02 Febrero 2021

Aprobación: 20 Septiembre 2021

Publicación: 08 Enero 2022

\section{Resumo:}

Contexto do caso: O presente caso para ensino narra os desafios e as emoções vivenciados na prática gerencial de João coordenador de um processo de mudança de fluxos de trabalho em uma organização pública. A narrativa descreve como as mudanças e os relacionamentos com colegas de trabalho e familiares influenciaram as emoções e o comportamento do protagonista. As experiências emocionais vivenciadas pelo gerente, tais como alegria, tristeza, raiva e medo, foram ocasionadas pela percepção de que uma decisão autoritária e centralizada da alta administração havia sido injusta.

Dilema do caso: Essa circunstância levou João a viver um dilema como gestor público: permanecer na função ou solicitar a sua exoneração. O objetivo do caso é refletir sobre as emoções básicas e os efeitos negativos da dissonância emocional e da ausência de estratégias de regulação emocional na vida familiar e no trabalho.

Fechamento do caso: Existem duas possibilidades de desfecho do caso e o leitor deve, a partir da análise do dilema, decidir que rumo o protagonista deveria seguir em sua carreira. As emoções assumem um papel determinante nesse processo de escolha.

Palavras-Chave: Emoções, Prática gerencial, Contexto público, Mudança organizacional.

\section{Abstract:}

Context of the case: This teaching case presents the challenges and emotions experienced by João in his management practice as coordinator of a change process in workflows in a public organization. The narrative describes how changes and relationships with co-workers and family members influenced the protagonist's emotions and behavior. The emotional experiences lived by the manager, such as joy, sadness, and fear, as well as anger were provoked by the injustice perceived from an authoritarian and centralized decision by top management.

The dilemma of the case: This circumstance led João to live a dilemma as a public manager: to remain in the role or to request his resignation. The aim of the case reflects on basic emotions, the negative effects of emotional dissonance and the emotional regulation strategies in family life and work.

Case closure: There are two possibilities for ending the case that the reader must, from the analysis of the dilemma, decide which path the protagonist should follow in his career. Emotions play a determining role in this choice process.

KEYWORDS: emotions, managerial practice, public context, organizational change.

\section{Resumen:}

Contexto del caso: Este caso de enseñanza narra los retos y emociones vividos en la práctica directiva de João como coordinador de un proceso de cambio de flujos de trabajo en una organización pública. La narrativa describe cómo los cambios y las relaciones con los compañeros de trabajo y los miembros de su familia influyeron en las emociones y en el comportamiento del protagonista. Las experiencias emocionales vividas por el administrador público, como alegría, tristeza y miedo, así como la rabia, fueron consecuencia de la injusticia percibida por el a partir de una decisión autoritaria y centralizada por parte de la alta dirección.

Dilema del caso: Esa circunstancia ha llevado João a vivir un dilema como administrador público: permanecer en el cargo o renunciar. El objetivo del caso es reflexionar sobre las emociones básicas, los efectos negativos de la disonancia emocional en el trabajo y las estrategias de regulación emocional en la vida familiar y laboral. 
Cierre del caso: Hay dos posibilidades para dar por finalizado el caso y el lector debe, a partir del análisis del dilema, decidir qué dirección debe seguir el protagonista en su carrera. Las emociones juegan un papel decisivo en este proceso de elección.

Palabras Clave: emociones, práctica directiva, entorno público, cambio organizacional.

\section{Contexto do Caso: o filme Divertidamente}

Após uma semana de muito trabalho, João chega em casa e seu filho de 10 anos corre para recebê-lo: "Pai, pai, hoje à noite a gente vai fazer uma sessão de cinema aqui em casa. A mamãe já preparou tudo. Vai ter até pipoca”. "Que coisa boa, meu filho! E a qual filme vamos assistir hoje?”, indagou João. “Divertidamente, pai. É um filme muito legal. A história tem muitos personagens que moram na cabeça de uma menina”, respondeu o filho, muito empolgado.

A esposa de João, Ana, percebe que ele está preocupado e, aparentemente, abatido. Ela o procura para conversar no quarto e pergunta: "Amor, o que aconteceu hoje no trabalho? Você parece abatido, triste. Estou preocupada". João olha nos olhos de sua esposa e, com tranquilidade, responde: "Hoje foi um dia difícil... A presidência tomou uma decisão sem a participação dos colaboradores. Menos servidores, mais metas, mais cobrança por produtividade, mais demandas e todo mundo tenso com a situação. Como gestor, estou me sentindo pressionado pela equipe... (João suspira). Mas falar em concurso público agora, com toda essa pressão do governo sobre os gastos com pessoal na Administração Pública, imagina? Não está fácil...”. A sua esposa o observa com um olhar compassivo e afirma: "Tente se desligar um pouco do trabalho. Vamos assistir ao filme com o Miguel. Foi uma indicação da psicóloga e ele está muito empolgado para ver”.

Assim que a sessão de cinema iniciou, João logo se identificou com a protagonista, Riley. A cada cena do filme, um misto de emoções emergia e fazia com que ele refletisse sobre sua experiência recente no projeto Transforma Digital. Sentimentos como tristeza, raiva e medo, faziam-no pensar que tinha fracassado. No entanto, quando ele refletia sobre a rede de relacionamentos que havia construído nos últimos anos, sentiase alegre. De repente, ele escuta a voz de seu filho bem distante: “Pai, o filme acabou. Vamos?". Sua esposa sorri e diz: "Parece que esse filme mexeu com você, amor".

A história de Riley teve um significado especial para João. Ana o observa e, conhecendo muito bem seu marido e sua realidade como gestor em uma organização pública, ressalta: "Amor, eu sei por que você está assim. Você ficou pensando no trabalho e imaginando que os personagens do filme estão comandando as emoções na sua cabeça, acertei?”. Emocionado, ele apenas acena com a cabeça concordando. Após o filme, por mais que tentasse evitar as suas emoçóes, João se sentia ansioso, com falta de ar e tremores nas mãos. Respirava fundo para tentar se acalmar, mas escapavam algumas lágrimas de seus olhos. As lembranças de quando esteve irritado em casa com sua esposa e seu filho não saíam de sua mente. Será que a sua ilha da família estava ameaçada? Sabia que algo precisava mudar...

Memórias alegres se misturam a memórias tristes. Com esse argumento inicial, o filme Divertidamente mostra como as mudanças podem influenciar nossas emoções. Quando Riley, uma adolescente de 12 anos, precisa se mudar em decorrência de uma nova oferta de trabalho recebida pelo seu pai, ela percebe que a vida não envolve apenas momentos felizes. Assim que a alegria perde o comando, suas memórias começam a adquirir novos sentidos emocionais. Riley vivencia um processo de transformação de sua personalidade, de suas motivações e do seu humor. O filme retrata as emoções básicas - alegria, tristeza, "nojinho" (aversão), medo e raiva - como personagens que interagem no "centro de comando" (na mente) da protagonista. Essas emoções modelam sua personalidade, a qual é ilustrada por ilhas - família, honestidade, amizade, diversão e hóquei - que vão sendo destruídas ao longo filme, de acordo com as experiências emocionais da personagem.

Com a transformação de sua personalidade, Riley passa a construir novas memórias e a atribuir novos significados emocionais às suas experiências. Enquanto ela evita emoções que considera negativas e busca para si aquelas tidas como agradáveis ou positivas, sente-se desequilibrada, perdida. A partir do momento, no entanto, em que acolhe o que está sentindo, ela compreende que as emoçóes podem ser boas e ruins ao 
mesmo tempo e consegue compartilhá-las com os outros. As emoções de Riley são validadas, por exemplo, quando seus pais escutam suas frustrações com a mudança de cidade. Eles não a julgam, muito pelo contrário, abraçam-na enquanto ela chora. Riley percebe que pode ressignificar experiências aceitando e validando suas emoções. Nesse processo, novos aspectos de sua personalidade são desenvolvidos para lidar com os eventos complexos e inéditos que surgem em sua vida.

As emoções de João foram evocadas diante da narrativa do filme. Servidor público federal concursado há 15 anos, ele ocupava a função gerencial há pelo menos 10 anos. Aos seus 42 anos de idade, sentia que a sua experiência no trabalho o ensinou a lidar bem com as pessoas, mas, nos últimos meses, percebia que algo nesse contexto estava afetando o seu equilíbrio emocional, manifestando-se, inclusive, através de sintomas de estresse em seu corpo. Ana, sua esposa, percebia que, há alguns meses, ele demonstrava cansaço, estresse e irritação em casa. O trabalho estava influenciando seu humor e suas relações familiares. João parecia irritado, não tinha mais paciência para orientar Miguel em suas tarefas da escola e se dispersava muito durante as brincadeiras. Também reclamava de dores de cabeça, tomava antiácidos para amenizar desconforto digestivo e já havia engordado cinco quilos nos últimos seis meses. Assim como Riley, João começou a imaginar que suas emoções construíam ilhas que modelavam sua personalidade. No caso dele, eram as ilhas da família, da estabilidade profissional, do bem-estar no trabalho e do gestor excelente. Após assistir ao filme, ele começou a pensar que essas ilhas estavam prestes a desmoronar. Será que, como Riley, ele deveria tentar consertar as coisas ou precisava aceitar e validar suas emoções a fim de construir novas ilhas para lidar com as situações complexas que se desenhavam à frente?

Para entender melhor a situação vivenciada por João, é necessário retornar dois anos no tempo para compreender as mudanças ocorridas em seu contexto de trabalho.

\section{O Trabalho de JoÃo}

João é bacharel em Administração. Ele atua como gestor de atendimento regional em uma autarquia pública federal (a partir de então, denominada APF) dirigida por um presidente, cinco superintendentes regionais e 27 gerentes estaduais.

No ano de 2019, a APF decidiu implantar o projeto Transformação Digital em todas as suas unidades, com o objetivo de prestar serviços públicos mais rápidos, transparentes e efetivos. Anteriormente, os requerimentos de serviços eram solicitados presencialmente, os atendentes formalizavam o processo físico e, quando possível, decidiam imediatamente quanto ao direito dos cidadãos. Quando esses requerimentos não eram concluídos durante o atendimento presencial, eles se acumulavam por dias, meses e anos. Justificavase que a escassez de pessoal em algumas unidades provocava esse acúmulo de serviço. Enquanto em alguns lugares o tempo médio de conclusão dos requerimentos era menos de 30 dias, em outros, poderia chegar a mais de um ano.

Com o projeto Transformação Digital, os processos físicos dariam lugar aos digitalizados, sendo assim, os requerimentos passariam a ser eletrônicos. Para tanto, emitiu-se uma portaria nomeando coordenadores estaduais do projeto. João foi um deles. A previsão de implantação em todo o Brasil era de um ano. Cada regional possuiria uma fila única de processos eletrônicos, os quais poderiam ser analisados por qualquer servidor de sua abrangência. Ao assumir essa coordenação, João se tornou responsável pela mudança nos fluxos de trabalho em mais de 50 unidades de atendimento. Além das funções que desempenhava como gestor de atendimento, novas atribuições surgiram: treinamento de servidores, formação de parcerias com o público externo e monitoramento de indicadores estratégicos. João respondia diretamente ao Gerente Estadual.

O trabalho de João era desafiador, pois enfrentava a resistência à mudança de seus colegas de trabalho e o desafio de entregar resultados com os poucos recursos disponíveis, o que demandava muita entrega emocional. Como gestor público, ele precisaria lidar com a dificuldade adicional de modificar normas, regulamentos e estruturas organizacionais. Isso seria mais flexível no setor privado. 
Para João, essa experiência exigiu novas competências gerenciais. Após seis meses de implantação do Transformação Digital no Estado, durante uma reunião, seu gerente imediato questiona: "João, está tudo correndo bem? Estamos há seis meses de finalizar a implantação do projeto. Ainda temos muitos desafios e muitas demandas de trabalho". Ele respondeu: "Tudo bem, mas parece que todas as técnicas que eu aprendi não fazem muito sentido se eu não buscar compreender as pessoas. Ser gerente, às vezes, pode exigir mais emoção do que razão". Seu chefe aquiesce, mas acrescenta: "Ainda assim, lembre-se que você tem apenas seis meses. Você é muito competente, mas precisa focar nas metas, ok?”. João se sente pressionado, tenso, ao imaginar o volume de trabalho restante, respira fundo e acena com a cabeça: "Tudo bem, senhor".

Há seis meses, João sentiu muita alegria com a nomeação para atuar como coordenador, mas, ao longo do tempo, foi percebendo os desafios e as responsabilidades dessa função e as implicações dela em seu comportamento e na sua relação com a família. Era como se as suas ilhas do bem-estar no trabalho e da família estivessem sendo ameaçadas.

\section{A Alegria de Ser Gestor}

Quando aceitou coordenar o Transformação Digital, João estava muito empolgado, pois poderia contribuir com a automatização dos fluxos de trabalho da APF. Ele acreditava que o projeto poderia ser a chave para uma organização de trabalho mais produtiva e efetiva. Um dos desafios encontrados por ele nos primeiros seis meses da coordenação foi a resistência à mudança por parte de alguns servidores, gestores e, principalmente, do público externo. As pessoas estavam tão acostumadas com o atendimento presencial e o processo físico que não conseguiam enxergar claramente os benefícios da mudança. Depois de muito esforço para conscientização dos envolvidos no processo, ele marcou as datas de implantação nas unidades.

Cada implantação era como uma festa para João. Ao chegar na unidade de atendimento da cidade onde realizaria a capacitação, ele recebia os colegas com um sorriso largo no rosto, gesticulava com vigor defendendo suas ideias. Estava tão animado que as pessoas eram contagiadas. Ao final, João percebia manchas vermelhas nos seus braços e no seu peito, além de sentir um calor diferente em seu corpo. Ele estava tão animado que não dava tanta importância àqueles sintomas físicos. Ao chegar em casa, relatava para sua esposa os detalhes do trabalho realizado com muita empolgação.

Nove meses se passaram desde a implantação do Transformação Digital na primeira unidade de atendimento no Estado. João e a equipe celebravam o envio do relatório para análise de seu superior imediato. Eles estavam muito satisfeitos e orgulhosos dos resultados do trabalho. O prazo foi cumprido com êxito. No momento do envio do relatório, João sentiu um calor invadir o seu corpo, um sorriso estampava o seu rosto e até sua pele se enrubescia. Era como se a alegria assumisse o controle da sua mente. As outras emoçóes estavam controladas, apenas observando a ilha do gestor excelente ser fortalecida. Entretanto, os ventos da mudança prometiam fortalecer outras emoções.

\section{Quando Surgiu a Tristeza}

Ao longo da implantação do projeto, não foi apenas a alegria que assumiu o protagonismo. Em alguns momentos, o sentimento de perder o controle influenciava o comportamento de alguns gestores. Muitas pessoas tinham dificuldade de requerer serviços eletronicamente, o que gerava inúmeras reclamações dos cidadãos.

Diante desse cenário, Pedro, um dos gestores de uma unidade de atendimento do interior do Estado, questionou: "João, você acha que as pessoas vão conseguir solicitar serviços apenas pela internet? Esse processo não excluiria a maioria da população, que é semianalfabeta ou analfabeta funcional?". Respondendo às inquietações do colega, João ponderou: "Nós precisamos ter calma. Essas mesmas pessoas ainda podem 
solicitar presencialmente os serviços em nossas unidades. Nós estamos apenas oferecendo alternativas digitais". Ainda inseguro, Pedro retrucou: "Mas nós somos pressionados pela alta administração a direcionar as pessoas para o requerimento eletrônico. Essas pessoas não têm celular, elas não têm acesso à internet. Nem sabem usar computador. Como elas vão acessar os serviços?”. Ao ouvir a conversa, Maria, gestora de outra unidade do interior, também oferece sua opinião: "Pedro, se essas pessoas conseguem utilizar o caixa eletrônico do banco, com certeza vão conseguir realizar requerimentos virtuais”. Vozes se confundiam na sala e parecia que todos falavam ao mesmo tempo. João ficava muito preocupado com a situação dos cidadãos e com as dificuldades dos gestores. $\mathrm{Na}$ sua mente, várias emoções tentavam assumir o controle.

Embora muitos usuários dos serviços fossem analfabetos, adotar meios eletrônicos era uma necessidade. João estava convicto de que era o melhor caminho para enfrentar a crise da escassez de pessoal, cuja perspectiva era se agravar em decorrência da previsão de aposentadoria dos servidores para os próximos dois anos. Os pedidos para novos concursos públicos não eram respondidos. A demanda por serviços se acumulava nas unidades. Para João, o Transformação Digital parecia ser a melhor alternativa para enfrentar essa situação.

No intuito de superar esses desafios, a APF propõe que sejam realizados acordos com organizações públicas, privadas e sociais, objetivando estabelecer parcerias com tais entidades externas para auxiliar os cidadãos em suas dificuldades operacionais no requerimento eletrônico de serviços. João coordenou a celebração desses acordos no Estado. Após tais ajustes no projeto, percebia-se maior inclusão digital, mas, os resultados em termos de celeridade e efetividade pareciam demorar mais do que o esperado. A pressão interna e externa aumentava a cada dia. Consequentemente, o sentimento de tristeza parecia querer assumir o controle na mente de João como, por vezes, ocorreu com Riley. Ele agia como um bom gestor para tentar minimizar os efeitos negativos da situação, evitava os pensamentos negativos, focava no trabalho que precisava fazer e buscava solucionar os problemas que surgiam. A busca incessante pela positividade camuflava emoções desagradáveis, pelo menos aparentemente.

A realocação de funcionários entre as equipes de trabalho demandava muito de João emocionalmente. A maioria das pessoas não queria mudar de função ou de lotação, muito menos as suas atribuições. A mudança, no entanto, era necessária para atender as demandas impostas pela nova realidade da organização e precisava ser coordenada por João. Ele sentia um peso muito grande nas costas, pois a vida de muitas pessoas dependia de suas decisões gerenciais. Os gestores procuravam João para reclamar das políticas de gestão da organização. Elogiavam a conduta dele, mas sentiam que eram muito solitários, mesmo estando rodeados por pessoas. Eles tinham a percepção de que a alta administração não lhes proporcionava o suporte adequado e que a insatisfação das equipes de trabalho atrapalhava os laços afetivos e as amizades estabelecidas.

Maria, percebendo João muito reflexivo, afirmou: "Os gestores se preocupam com emoções de sua equipe frequentemente. Mas quem se preocupa com as emoções dos gestores?”. A fala de Maria levou João a sentir que sua energia positiva fugia de seu corpo. Ele olhava para si e para tudo o que ocorria ao seu redor. Após nove meses de implantação do projeto, aquele vigor e ânimo que ele sentira na inauguração do Transformação Digital, os quais lhe ofereciam um filtro colorido para enxergar o entorno, estavam dando lugar a emoções que emprestavam um tom mais cinza a essas mesmas lentes. Ele se esquecia de comer e, quando lembrava, comia demais. Suas roupas estavam ficando apertadas. Recordou que, diante de tanta pressão, passou a sentir desconfortos digestivos.

João se sentia frustrado e decepcionado por ver que seu projeto não estava tão promissor quanto antes. Além disso, não se sentia motivado a trabalhar da mesma forma. Ele também imaginava os desafios futuros, uma vez que, se desejasse se aposentar como servidor público, ainda ficaria na organização por, no mínimo, 23 anos antes de sua aposentadoria.

Para não expressar a tristeza no ambiente de trabalho, João, todos os dias, conscientemente a evitava. Esboçava um sorriso, transmitia calma e confiança aos seus colegas e se empenhava para acreditar que tudo se resolveria. No final do dia, todo aquele esforço para parecer alegre no trabalho roubava suas energias. Ele achava muito difícil estar bem para brincar com seu filho e conversar com sua esposa, pois, quando chegava 
em casa, só tinha vontade de se isolar, descansar e dormir. Assim como ocorria com Riley, era muito cansativo evitar a tristeza, por isso as ilhas do bem-estar no trabalho e do gestor excelente pareciam desmoronar.

\section{A Injustiça que Causa a Raiva}

Após uma reunião com a presidência da APF, João voltou para a sua sala com muita dor de cabeça. Estava respirando fundo para se acalmar, mas a sua vontade era de gritar. "Quanta raiva!", pensava ele. A sensação de injustiça levou João a perder o controle na presença de sua equipe. Ele bateu a mão na mesa, perplexo, sem acreditar na decisão de criar uma fila única nacional de processos eletrônicos. Antes da implantação do Transformação Digital, o tempo médio de espera de conclusão dos processos na regional era de 12 meses. Após a implementação do projeto, com o esforço coordenado das gerências estaduais, esse prazo caiu para três meses. Com a decisão da fila única, as cinco regionais compartilhariam a mesma fila e o tempo médio de espera subiria para 18 meses. A alta administração da APF tomou uma decisão sem consultar as regionais e os coordenadores estaduais e comunicou a todas as unidades de atendimento sem discussão prévia com os gestores locais.

Durante muito tempo, João construiu uma rede de relacionamentos com entidades públicas e privadas, cidadãos, servidores e gestores. Com essa decisão, a rede parecia estar ameaçada. João rapidamente se recompõe e pensa: "Eu não posso demonstrar fraqueza agora. As pessoas esperam que eu seja confiável e resolva esse problema”. Ele se desculpa com sua equipe por perder o controle e afirma que tudo vai ser resolvido e que ninguém precisa se preocupar.

As equipes das unidades de atendimento também acharam injusta a decisão e isso afetou o clima no ambiente de trabalho. A raiva impactou na produtividade - os gestores relataram a João que não conseguiam motivar suas equipes como antes. Como coordenador do projeto, João procurou dialogar com as equipes a continuarem apoiando o Transformação Digital. Elas costumavam ser engajadas e satisfeitas, mas a notícia de unificação das filas regionais poderia prejudicar seus desempenhos. João participou de uma reunião com os gestores das regionais. Durante o encontro, a maior preocupação de todos estava na definição da melhor estratégia para comunicar suas equipes sobre a decisão tomada pela presidência. Eles reclamavam que não haveria necessidade de gestores locais se a APF tomasse decisões daquela forma autoritária e centralizada.

Após a reunião, João arrumou sua sala e resolveu ir para casa. Embora tentasse não pensar nesse assunto, estava tão irritado que não conseguia desviar seus pensamentos. Ele não acreditava que aquilo estivesse acontecendo. Chegou em casa muito abatido com a sua situação e preferiu ir para o seu quarto descansar um pouco. Alguns dias após a deliberação, já sentia o impacto da medida pelo excesso de ligações de colegas de trabalho e de parceiros externos reclamando dos prazos. Por mais que ele explicasse a situação e tentasse convencê-los com calma de que ela se resolveria, internamente ainda sentia muita raiva. Aquilo fazia com que ele se percebesse como uma bomba-relógio, prestes a explodir. No trabalho, ele estava tão tenso que ficava nervoso, impaciente, e perdia a calma com facilidade. Sentia tremores no corpo, falta de ar, agitação e ansiedade. Um colega de trabalho um dia lhe disse que "quando a boca cala, os órgãos falam e adoecem”. João percebia exatamente isso acontecer com ele.

Ao final do dia, ele se encontrava tão cansado que só pensava em chegar em casa, tomar um banho e ir dormir. Sua família, no entanto, sentia sua falta. Seu filho dizia que queria ser seu trabalho por um dia para ter a atenção do pai só para ele. Algo precisava ser feito. Mais uma vez, João evitava demonstrar irritação no trabalho e em casa. Mesmo com toda a tensão em seu corpo, esforça-se para transmitir alegria, calma e confiança. Ele tentava mostrar que tinha o controle da situação. Mas a que preço? O que João estava disposto a perder? 


\section{A Aversão a uma Decisão}

Diante das dificuldades enfrentadas com a decisão de centralização dos processos, João tenta dialogar com os envolvidos no conflito, mas a presidência não muda a estratégia. Ele sente que precisa continuar a motivar suas equipes, mas não concorda com a decisão. Imagina que, se trabalhasse em uma empresa privada, seria demitido por seu comportamento, mas, ao menos, teria direito a seguro-desemprego e ao Fundo de Garantia por Tempo de Serviço. Talvez fosse exonerado de sua função como gestor estadual por não concordar com a presidência, entretanto, graças à estabilidade, não poderia ser exonerado de seu cargo público na APF. O sentimento de aversão à decisão parecia estar estampado em sua face. Ele não conseguia modular as reações de seu corpo aos seus sentimentos.

Depois de buscar recursos para se acalmar no ambiente de trabalho, João vai ao banheiro e procura refletir sobre o que está acontecendo e percebe como essa experiência está afetando as suas emoções. Após alguns minutos, volta para a sua sala com uma aparência mais calma e equilibrada. Esse conflito entre a mente e o corpo causa uma exaustão emocional nele, a ponto de sua ansiedade se expressar através de dores no corpo, sobretudo, na cabeça e problemas no estômago. Ele sente que seu corpo não consegue digerir aquela experiência emocional intensa.

Em mais uma reunião de trabalho, João tenta acalmar as equipes das unidades de atendimento. Elas se mantêm coesas, muito mais pela confiança em João do que na organização em si. Sua responsabilidade como líder e elo entre a presidência e as equipes de trabalho locais exige grande demanda emocional. Ele estava se sentindo muito cansado e a equipe percebia que isso era consequência dos conflitos ocasionados pela decisão autocrática da organização.

Ao chegar ao trabalho na segunda-feira, João começou a perceber uma sensação de repulsa. Estar naquele ambiente desencadeava tristeza, dores no estômago e enjoos, mas nem todos pareciam estar reagindo assim. Os colegas tinham superado aquele problema e aceitado a nova realidade mais facilmente do que ele? Por que o trabalho estava lhe fazendo tanto mal? Ele não conseguia pensar com clareza.

Essa repulsa fez com que João começasse a questionar o seu papel como gestor público na APF. Será que não seria o momento de repensar a sua posição na coordenação do Transforma Digital? Ao enfrentar esse dilema, ele resolveu conversar com sua esposa, que acolheu seus sentimentos, ofereceu um abraço e disse que apoiaria sua decisão. Olhando em seus olhos, ela disse: "Meu amor, nós te amamos e queremos que você esteja bem. Estou muito preocupada com sua saúde e com o seu bem-estar físico e mental. Miguel também está sentindo a sua falta". João abraçou a sua esposa e chorou. Entendeu que precisava refletir antes de tomar uma decisão definitiva.

\section{O Medo e a Sobrevivência}

Diante de tantos desafios e dificuldades, João sentia medo de deixar o cargo e as suas equipes não conseguirem finalizar as mudanças nos fluxos de trabalho e as novas deliberações da alta administração da organização. Ao longo de dois meses, permaneceu na gestão do Transforma Digital. Apesar de o clima organizacional ainda estar muito conturbado, as equipes regionais se adaptaram à decisão da empresa de unificar as filas regionais.

Aliada a essa tensão interna, uma crise econômica e política se instalava no país, gerando incertezas quanto à sobrevivência da organização a longo prazo. Os gestores estavam com medo do futuro e João compartilhava desse sentimento. Ele imaginava que o possível novo cenário traria danos para si, para a organização e para a sociedade. Tinha dias que ele ficava em alerta; em outros, parecia paralisado. Não deixava, no entanto, seus colegas perceberem. Ele demonstrava confiança em suas palavras, esboçava um sorriso e se mantinha positivo, embora, internamente, estivesse muito ansioso. Quando o medo chegava, o seu coração acelerava, a respiração ficava muito curta, suas mãos suavam e ele tentava se esquivar desse sentimento. 
As dúvidas quanto a continuar na gestão pairavam em sua mente. Essa decisão significaria menos tempo dedicado ao trabalho e mais disponibilidade para cuidar de si mesmo e da família. Concomitantemente, entretanto, representaria renúncia a uma posição de responsabilidade em uma atividade que ele tanto almejou e que o fez feliz por um longo período. Além desses fatores, João sabia que seu salário diminuiria e ele precisaria reajustar seus gastos e se adaptar a um novo estilo de vida. Ele tinha medo de continuar sendo gestor, mas também, de deixar a gestão. Sentia-se paralisado, sem saber como agir.

Ao chegar em casa, João não conseguia compartilhar esse medo com sua família. Ele não queria que eles se preocupassem com o futuro, nem com a sustentabilidade financeira da casa. Ele já planejava, no entanto, diminuir os gastos domésticos em alguns aspectos que não considerava essenciais, diante da possibilidade de deixar a gestão e de precisar se adaptar a uma vida mais simples. Essa situação o deixava com medo de que a ilha da família ou a ilha da estabilidade profissional desmoronasse, assim como parecia acontecer com a ilha do bem-estar no trabalho e do gestor excelente.

\section{Dilema do Caso: Ser ou NÃo Ser - EIS a GeStÃo}

As experiências emocionais de João, em seu trabalho e na família, impactaram as suas motivações. Nas conversas com seus pares, começava a pairar a dúvida: vale a pena ser gestor público? $\mathrm{O}$ trabalho do gestor realmente parecia ter um aspecto emocional relevante, pois as emoções davam cores aos papéis gerenciais. João e seus colegas sentiam que esses papéis haviam ganhado contornos muito cinzas, que provocavam tempestades no trabalho e na vida familiar. Sobre esse assunto, um dos gestores de sua equipe de atendimento afirmava: "Quem está na chuva é para se molhar!”. “Mas essa chuva já virou tempestade há alguns meses...", pensava João.

Os gestores da regional eram muito competentes do ponto de vista técnico. No entanto, não estavam conseguindo lidar com tantas mudanças. Sentiam-se tristes, insatisfeitos e injustiçados. Os pensamentos e os valores da organização não eram compartilhados entre os gestores da regional, que buscavam João para compartilhar problemas e relatar reclamações tanto de colegas da equipe quanto de clientes. Um diálogo com dois gestores de sua equipe não saía da sua cabeça: "Nós precisamos desenvolver várias habilidades para ajudar a criar um ambiente de trabalho saudável para nossa equipe, no entanto, eu me pergunto: quem nos ajuda a lidar com as nossas emoções? Será que gestores não adoecem?”. Outro gestor de equipe concorda e complementa: "Nós não temos treinamento sobre como lidar com as nossas emoções, enfrentamos muitas dificuldades com a escassez de equipamentos e material. Temos que dar nó em pingo d'água todos os dias. Mas qual é a preocupação que a alta administração está tendo conosco?”.

Quase um ano após a implantação do projeto, João percebeu que estava o tempo todo querendo que emoções positivas estivessem no "centro de controle" de sua mente, mas então ele lembrou de Riley, personagem do filme Divertidamente. Ela precisou aceitar que estava triste com a situação que vivia para poder se equilibrar emocionalmente. As ilhas que modelavam sua personalidade haviam desmoronado? Outras demandariam ser criadas? Será que João precisava aceitar e validar suas emoções? Essas perguntas ecoavam na sua mente: ser ou não ser - eis a questão. João precisava tomar uma decisão em sua vida para conciliar as demandas do trabalho com a vida familiar. Ele continuou a se questionar se deveria ou não continuar sendo gestor naquela organização.

O principal motivo pelo qual João aceitou ser gestor público, além da questão financeira, envolvia uma missão social de melhorar a vida das pessoas, por meio da qualidade na prestação de serviços. Com as experiências vivenciadas como gestor, entretanto, ele começou a perceber que não tinha mais tanta autonomia para tomar decisões quanto antes, que as equipes estavam cada vez mais insatisfeitas e que não havia muito espaço para negociação dentro da empresa. Em contrapartida, ele conseguiu estabelecer uma rede de relacionamentos muito forte com entidades públicas e privadas, com as equipes de trabalho e com outros gestores na organização. João se sentia responsável pelo bem-estar dessa rede. Ele ainda conseguia 
excelentes resultados em termos de produtividade e engajamento das equipes. Também se sentia desafiado em seu trabalho. Além disso, raramente conversava abertamente sobre as emoções vivenciadas no trabalho com outras pessoas, além de sua esposa. Mesmo com ela, apesar da confiança, não conseguia compartilhar plenamente os seus medos e adotou alguns comportamentos que desencadearam conflitos nas relações familiares.

João até pensou em buscar ajuda profissional médica e psicológica, mas teve receio de isso prejudicar a sua imagem e de as pessoas de sua equipe julgarem que ele não era competente o suficiente para atuar como gestor. Um amigo lhe indicou um programa de mindfulness [1] para lidar com o estresse, mas ele não chegou a participar. Ele também pensou em voltar a praticar exercícios físicos regularmente e buscar auxílio de uma nutricionista para se alimentar melhor e aprender a lidar com aquela situação. Apesar de ter consciência de que precisava mudar, nenhuma das ideias foi executada. Para lidar com as situações de estresse e os sintomas em seu corpo, ele usava analgésicos, tomava chá para dormir, antiácidos para desconforto digestivo e, de vez em quando, gostava de tomar uma cerveja com os amigos. Essas estratégias, no entanto, eram paliativos e não geravam os efeitos esperados.

João precisava agir. Não podia continuar sofrendo as consequências de suas escolhas. Estava prestes a perder o controle emocional. Ao pensar sobre isso, ele sentia raiva, tristeza, medo e até um "nojinho" do cenário formado na organização em que trabalhava. Não conseguia, entretanto, compreender bem essas emoções e nem reconhecer as reações ocasionadas por elas em seu corpo e em seu comportamento. O filme Divertidamente foi o gatilho emocional que despertou nele a necessidade de refletir sobre sua vida pessoal e profissional. Entretanto, João pensava, pensava e pensava, mas não agia. E o dilema continuava: ser ou não ser - eis a gestão.

\section{NOTAS DE ENSINO}

\section{ObJetivos de Aprendizagem}

Este caso aborda a temática da gestão das emoções na prática gerencial no contexto público. A sua utilização no ensino objetiva levar os alunos a:

- Identificar as implicações das emoções básicas na prática gerencial e na vida em família;

- Compreender a relação entre emoções, comportamento e relações interpessoais no trabalho e em família;

- Refletir sobre o efeito da dissonância emocional no bem-estar e na saúde mental;

- Tomar decisões profissionais e pessoais fundamentadas na análise das emoções experienciadas.

\section{Fontes De Dados}

Embora o caso se baseie em um contexto da vida real, uma organização pública, seus personagens e situações são fictícios. O caso foi elaborado a partir de duas fontes de dados: o filme Divertidamente e entrevistas realizadas com gestores públicos.

\section{Aplicações do Caso}

Este caso pode ser utilizado em cursos de graduação e de pós-graduação lato sensu e stricto sensu em disciplinas de Comportamento Humano nas Organizaçôes, Administração de Recursos Humanos, Cultura e Mudança nas Organizações Públicas, Liderança, Aprendizagem. Gestão das Emoções no Contexto Público. 


\section{Sugestão de Questões Para Discussão}

As questões para discussão objetivam suscitar a reflexão dos alunos sobre dilemas emocionais comuns aos gestores de organizações públicas. Também permitem levar os alunos a compreenderem o papel das emoções em sua atividade profissional e auxiliá-los a percebê-las, gerenciá-las e refletirem sobre a sua influência em seu comportamento no trabalho e na vida. Recomenda-se, assim, que o professor utilize as seguintes questóes:

1. O filme Divertidamente retrata como as cinco emoções básicas - alegria, tristeza, medo, raiva e "nojinho" - afetam a mente e o comportamento de Riley. Considerando esse filme, aponte o efeito das emoções básicas no corpo, no comportamento gerencial e nas relações familiares de João.

2. A dissonância emocional ocorre quando expressamos uma (ou mais) emoção(ões) externamente, enquanto experimentamos internamente outra(s). Por que João experienciava constantes episódios de dissonância emocional em sua prática gerencial? Quais foram os resultados da dissonância emocional na vida dele?

3. Ser ou não ser - eis a gestão: se você estivesse no lugar de João, continuaria na função de gestor público? Justifique sua resposta e indique o que você faria para se sentir melhor no trabalho e em casa.

\section{Planejamento da Aula}

Para aplicação do caso, recomenda-se que o professor já tenha abordado em sala de aula os seguintes tópicos: (a) contexto de mudanças e atuação do gestor; e (b) liderança e gestão das emoções. Inicialmente, o professor deve incluir em seu cronograma a data prevista para análise. Recomendamos que o caso seja encaminhado aos alunos com, no mínimo, oito dias de antecedência da data da aplicação em sala de aula. Como o caso também aborda o filme Divertidamente, o professor pode sugerir aos alunos que assistam ao filme antes da aula. Uma alternativa é trazer partes do filme no intuito de introduzir a temática das emoções na análise do caso. Para aplicação em sala de aula, sugerimos duas modalidades: duas ou quatro horas-aula. Essa proposta é fundamentada em Silva e Bandeira-de-Mello (2021).

a) Aplicação em duas horas-aula: os alunos devem analisar o caso e responder as questões antes do dia da aula. Ao iniciá-la, o professor pode organizar o layout da sala em um grande círculo e estruturar o processo de análise das questões do caso. Cada questão deve ser discutida em até 30 minutos. Antes de iniciar a discussão da primeira questão, o professor pode apresentar as seguintes perguntas: o que vocês acharam da história vivenciada pelo servidor público em sua prática gerencial? Vocês já vivenciaram alguma situação similar? Como vocês analisam o papel das emoções no trabalho e na vida pessoal? Em seguida, o professor pode introduzir as questóes do caso e solicitar aos alunos que apresentem suas respostas individualmente.

O professor pode utilizar o quadro branco ou um slide do PowerPoint para identificar os pontos centrais das respostas e, ao final de cada questão, refletir sobre os aspectos principais à luz da teoria, apresentando os quadros indicados como parâmetro de resposta das questões. Como a última questão envolve uma decisão, sugerimos que o professor divida a turma em dois grupos: um deles defenderá a permanência de João no cargo e outro, o seu afastamento da função gerencial. Os grupos devem apresentar argumentos plausíveis e fundamentados no caso para balizar a decisão.

Ao final da discussão das três questões, o professor terá ainda 30 minutos para apresentar uma síntese dos principais pontos abordados na discussão, levando a turma a perceber a complexidade de uma decisão no contexto público e o papel da subjetividade na gestão. Os alunos devem entregar ao professor suas respostas, que poderão ser utilizadas como parte do processo avaliativo da disciplina. 
b) Aplicação do caso em quatro horas-aula: nessa modalidade de aplicação, ao iniciar a aula, o professor pode formar grupos aleatórios de até cinco alunos e verificar se todos responderam as questões do caso. Essa ação é fundamental para o bom andamento das atividades. Caso algum aluno não tenha resolvido as questões do caso, recomenda-se que resolva as questões individualmente durante a aula. Ao formar os grupos, a sessão de análise ocorre em dois momentos: (a) discussão nos minigrupos (duas horas-aula); e (b) discussão com toda a turma mediada pelo professor (duas horas-aula).

Nas duas primeiras aulas, cada grupo deverá discutir as respostas de cada uma das questões e elaborar suas reflexões coletivas a partir das respostas individuais. Quando o grupo não chegar a um consenso, as respostas devem trazer os argumentos divergentes e as dificuldades no processo de análise grupal do caso. Cada grupo elaborará um pequeno relatório com as respostas coletivas das questões e uma reflexão do grupo com as principais dificuldades encontradas na resolução do caso.

$\mathrm{Na}$ segunda parte da aula, a discussão será mediada pelo professor e envolverá toda a turma. $\mathrm{O}$ ambiente deve primar pelo acolhimento de argumentos divergentes, mas fundamentados nas informações do caso e na teoria subjacente (emoções básicas, dissonância emocional e regulação emocional). No início, o professor pode introduzir a discussão de cada uma das questões utilizando as mesmas perguntas indicadas na modalidade 'A' e solicitando o posicionamento dos grupos. Ao longo da discussão, é fundamental identificar pontos convergentes e divergentes e utilizar os parâmetros de resposta e a teoria subjacente ao caso. $\mathrm{O}$ tempo para discussão de cada questão é de até 30 minutos.

Durante a análise do caso, o professor também pode apresentar cenas do filme e questionar os alunos em que situações do caso determinadas emoções básicas estavam presentes no comportamento do gestor público. Como a última questão envolve um dilema, o professor pode dividir a turma em dois grupos e realizar uma dramatização com os personagens indicados no caso. Um dos grupos dramatizará uma situação que sinaliza a permanência de João na função de gestor, e o outro grupo fará uma encenação representando a decisão de João pela sua exoneração da função de gestor público.

Nas duas modalidades, o professor deverá assumir o papel de facilitador, evitando opinar de forma pessoal sobre as questões analisadas para que os alunos desenvolvam competências de argumentação crítica, de respeito pela opinião do outro e de construção de um consenso coletivo, o que inclui opiniões alheias divergentes das opiniões pessoais. Para mediar a discussão, o professor poderá utilizar uma apresentação com slides, contendo informações sobre o caso, os quadros 1 e 2 indicados na seção Análise do Caso e conceitos relevantes da literatura. $O$ professor também deve utilizar o quadro para sistematizar as respostas dos alunos.

\section{ANÁlise do CASo}

A primeira questão do caso tem o seguinte enunciado: o filme Divertidamente retrata como as cinco emoções básicas - alegria, tristeza, medo, raiva e "nojinho" - afetam a mente e o comportamento de Riley. Considerando esse filme, aponte o efeito das emoções básicas no corpo, no comportamento gerencial e nas relações familiares de João.

O professor deve introduzir essa questão trazendo alguma cena do filme, como também perguntando aos alunos se eles assistiram a ele. Em seguida, o professor deve levar os alunos, dependendo da modalidade de aplicação do caso escolhida, a apresentarem as suas reflexões, utilizando o quadro branco ou um slide do PowerPoint para identificá-las. Ao final da discussão, o professor pode realizar uma análise das respostas à luz da literatura.

Para fundamentar teoricamente seus argumentos, o professor deve levar os alunos a refletirem que as emoções provocam alterações no corpo, nas expressões faciais e corporais e no comportamento. Esse argumento pode ser fundamentado em Ekman (2011), Goleman (1999) e Leahy, Tirch e Napolitano (2013). 
A reflexão teórica sobre as emoções básicas deve ter sido realizada nas aulas que antecederam a análise do caso, conforme sugerido no planejamento da sua aplicação.

Conhecer bem as emoções e como reagimos a ela é uma habilidade denominada Consciência Emocional, definida por Silva e Macêdo (2021, p. 571) como a "capacidade de reconhecer e compreender os sentimentos e as emoções de si próprio e dos outros, mantendo uma atitude compassiva, de confiança mútua, agindo com empatia nos relacionamentos e na tomada de decisão". Consideramos que tal habilidade pode ser aprendida, pois temos a capacidade de pensar sobre nossas emoções, refletir sobre nossas reações a elas e tomar decisões com base nesse processamento emocional.

Essa capacidade de processamento emocional constitui o que chamamos de Inteligência Emocional (BarOn, Costa, \& Parker, 2002; Kotsou, Mikolajczak, Heeren, Grégoire, \& Leys, 2019). Ela é fundamental para o bem-estar no trabalho e nas relações familiares, especialmente em posições de liderança, nas quais cerca de 90\% das habilidades demandadas são de Inteligência Emocional (Goleman, 1999). Ekman (2011) defende que nascemos com a capacidade de expressar e experimentar ao menos seis emoções básicas: raiva, alegria, tristeza, aversão, medo e surpresa. Contudo, ao longo de nossas experiências na vida, aprendemos emoções complexas por meio da nossa cultura e das interações sociais. O filme Divertidamente destaca cinco dessas seis emoções básicas e ilustra como elas modelam a motivação, os traços de personalidade e as escolhas na vida.

Para ilustrar seus argumentos, o professor pode apresentar estudos como o de Ekman (2011) sobre as emoções básicas na aula que antecede a análise do caso, uma vez que tais estudos defendem que as pessoas expressam emoções no corpo, no comportamento e nas relações familiares de forma similar, mesmo em culturas diferentes. Isso gera informações relevantes que podem ser processadas cognitivamente por pessoas emocionalmente inteligentes, subsidiando decisões importantes na vida e no trabalho e predizendo um desempenho e bem-estar superior nesses contextos, como defende Goleman (1999). Uma reflexão importante a ser colocada pelo professor é que as emoções básicas estão presentes em todas as pessoas e elas são interdependentes, ou seja, estão relacionadas entre si e se influenciam mutuamente.

Após a discussão teórica, para finalizar a análise da questão, o professor pode apresentar o Quadro 1, que aponta o efeito das emoções básicas de João no corpo, no comportamento gerencial e nas relações em família, levando os alunos a perceberem se esses efeitos também foram identificados por eles na análise do caso. 
José Wilker De Lucena Macedo, et al. SER OU NÃo SER - EIS A GESTÃo: as emoções na prática Gerencia...

Quadro 1: Efeito das emoções de João no corpo, comportamento gerencial e relações em família

\begin{tabular}{|c|c|c|c|}
\hline Emoção & Corpo & $\begin{array}{l}\text { Comportamento } \\
\text { gerencial }\end{array}$ & Família \\
\hline Alegria & \begin{tabular}{|l} 
Seu corpo \\
demonstrava \\
alegria por \\
meio do sorriso \\
e da pele \\
enrubescida e \\
aquecida. Ele \\
acordava de \\
bom humor, \\
cantarolando e \\
disposto para o \\
trabalho. \\
\end{tabular} & $\begin{array}{l}\text { Vigor, energia e } \\
\text { bem-estar no } \\
\text { trabalho. João se } \\
\text { sente mais } \\
\text { confiante, mais } \\
\text { produtivo e mais } \\
\text { satisfeito. Motiva a } \\
\text { equipe e constrói } \\
\text { uma forte rede de } \\
\text { relacionamentos. }\end{array}$ & $\begin{array}{l}\text { João tinha } \\
\text { conversas } \\
\text { agradáveis } \\
\text { com sua } \\
\text { esposa, } \\
\text { contribuía } \\
\text { para o seu } \\
\text { bem-estar } \\
\text { familiar. }\end{array}$ \\
\hline Tristeza & \begin{tabular}{|l} 
João sentia os \\
ombros caidos \\
e o corpo \\
encurvado. \\
Desenvolveu \\
transtornos \\
alimentares e \\
indisposição \\
para levantar- \\
se e ir \\
trabalhar. Ele \\
achava que a \\
vida estava \\
mais cinza. \\
\end{tabular} & $\begin{array}{l}\text { João se sentiu } \\
\text { decepcionado e } \\
\text { frustrado como } \\
\text { trabalho. Ele se } \\
\text { sentia triste e } \\
\text { solitário na gestão. } \\
\text { Diminuiu seu } \\
\text { ânimo, a motivaçăo } \\
\text { e o vigor para o } \\
\text { trabalhar. }\end{array}$ & \begin{tabular}{|l} 
Joẫo \\
negligenciava \\
as \\
necessidades \\
de sua esposa \\
e de seu filho.
\end{tabular} \\
\hline Raiva & $\begin{array}{l}\text { João sentia } \\
\text { tremores, } \\
\text { agitação, falta } \\
\text { de ar e } \\
\text { ansiedade. Não } \\
\text { conseguia } \\
\text { transmitir tanta } \\
\text { calma e } \\
\text { confiança como } \\
\text { antes. }\end{array}$ & $\begin{array}{l}\text { João perdia o } \\
\text { controle no } \\
\text { trabalho. Estava } \\
\text { irritado, tenso e se } \\
\text { chateava } \\
\text { facilmente, o que } \\
\text { lhe causou } \\
\text { problemas de } \\
\text { relacionamento } \\
\text { com os colegas de } \\
\text { trabalho. Sua } \\
\text { capacidade de } \\
\text { pensar com clareza } \\
\text { era bloqueada, não } \\
\text { conseguia } \\
\text { transmitir tanta } \\
\text { calma e confiança } \\
\text { como antes. }\end{array}$ & $\begin{array}{l}\text { João perdia o } \\
\text { controle em } \\
\text { casa. Estava } \\
\text { irritado, tenso } \\
\text { e se chateava } \\
\text { facilmente, o } \\
\text { que lhe } \\
\text { causou } \\
\text { problemas de } \\
\text { relacionamento } \\
\text { na familia. }\end{array}$ \\
\hline Aversão & $\begin{array}{l}\text { João sentia } \\
\text { dores no corpo, } \\
\text { dores de } \\
\text { cabeça, } \\
\text { problemas no } \\
\text { estômago e } \\
\text { enjoos. }\end{array}$ & $\begin{array}{l}\text { João sente repulsa } \\
\text { pelo trabalho e } \\
\text { deseja deixar de } \\
\text { ser gestor. Esconde } \\
\text { reaçôes corporais } \\
\text { dos colegas de } \\
\text { trabalho (dores no } \\
\text { corpo, dores de } \\
\text { cabeça, problemas } \\
\text { no estômago e } \\
\text { enjoos). }\end{array}$ & $\begin{array}{l}\text { Joăo } \\
\text { compartilha } \\
\text { seus } \\
\text { sentimentos } \\
\text { de repulsa } \\
\text { pelo trabalho } \\
\text { com sua } \\
\text { esposa, que } \\
\text { acolhe e valida } \\
\text { suas emoçóes. }\end{array}$ \\
\hline Medo & $\begin{array}{l}\text { João sentia } \\
\text { ansiedade, o } \\
\text { que lhe } \\
\text { causava } \\
\text { coração } \\
\text { acelerado, } \\
\text { respiração } \\
\text { curta e suor } \\
\text { nas mãos. Ele } \\
\text { estava tenso e } \\
\text { irritado. } \\
\text { Também } \\
\text { apresentava } \\
\text { dores de } \\
\text { estômago, } \\
\text { aumento de } \\
\text { peso e calor na } \\
\text { pele. }\end{array}$ & $\begin{array}{l}\text { Joăo se mantinha } \\
\text { ora em alerta, ora } \\
\text { paralisado. Evitava } \\
\text { que seus colegas } \\
\text { de trabalho } \\
\text { percebessem } \\
\text { qualquer } \\
\text { "fraqueza" ou } \\
\text { sentimentos que } \\
\text { ele considerasse } \\
\text { negativos. Sentia } \\
\text { dúvidas se } \\
\text { continuaria como } \\
\text { gestor. Participava } \\
\text { de algumas } \\
\text { reuniőes de forma } \\
\text { acalorada para } \\
\text { defender a si ea } \\
\text { sua equipe. }\end{array}$ & $\begin{array}{l}\text { João não } \\
\text { conseguia } \\
\text { compartilhar o } \\
\text { medo com sua } \\
\text { família. Ele } \\
\text { não queria } \\
\text { que eles se } \\
\text { preocupassem } \\
\text { com o futuro, } \\
\text { nem com o } \\
\text { sustento da } \\
\text { casa. Ele } \\
\text { tentava } \\
\text { diminuir os } \\
\text { gastos da } \\
\text { familia com o } \\
\text { objetivo de se } \\
\text { adaptar a uma } \\
\text { vida mais } \\
\text { simples. Como } \\
\text { a família não } \\
\text { compreendia o } \\
\text { real motivo da } \\
\text { redução dos } \\
\text { custos, eles se } \\
\text { magoavam } \\
\text { com as ações } \\
\text { de João. }\end{array}$ \\
\hline
\end{tabular}


Ao analisar o Quadro 1, o professor pode levar os alunos a perceberem a importância da compreensão e da gestão das emoções no corpo, no comportamento e nas relações em família, além de expor como o contexto da atuação do servidor público impacta em seu comportamento e em sua vida pessoal. Sobre o medo e a vivência de emoções na prática gerencial, o professor pode apresentar as reflexões de Silva (2009, pp. 231-245) sobre os resultados de uma pesquisa realizada com gerentes em um contexto diferente do público, mas que revela a importância de quem atua nesse cargo refletir sobre suas experiências de medo e sobre formas de mobilizar recursos emocionais para lidar com novas experiências. Como destaca o autor, familiarizar-se com o medo é uma oportunidade de crescimento pessoal, um desafio proporcional ao tamanho do risco e uma forma de autoconhecimento, tendo em vista que a melhor maneira de o aceitar é reconhecendo-o como uma emoção natural do ser humano (Silva, 2009).

A segunda questão apresentava o seguinte enunciado: a dissonância emocional ocorre quando expressamos uma (ou mais) emoção(ões) externamente, enquanto experimentamos internamente outra(s). Por que João experienciava constantes episódios de dissonância emocional em sua prática gerencial? Quais foram os resultados disso a longo prazo? A análise da questão pode partir da seguinte pergunta: o que é uma dissonância emocional? Robbins, Judge e Sobral (2010) definem dissonância emocional como as "inconsistências entre as emoções que sentimos e a que projetamos". Esse comportamento era muito comum na vida de João, sobretudo no trabalho, onde realizava um esforço emocional para expressar as emoçóes desejadas pela organização em seus relacionamentos interpessoais, o que, muitas vezes, desafiava-o a projetar uma emoção enquanto sentia outra (Robbins et al., 2010). Uma discussão específica no contexto da atuação do gestor público pode ser encontrada em Silva e Macêdo (2021), que enfatizam os efeitos da gestão das emoções no bem-estar e na saúde dos servidores públicos no ambiente de trabalho.

As emoções podem ser avaliadas como positivas ou negativas pelos indivíduos, de acordo com a percepção de prazer ou de sofrimento que elas podem causar. A constante experiência de dissonância emocional no trabalho pode adoecer as pessoas. Exige-se um esforço intenso e constante para expressar emoções positivas quando se vivenciam emoções negativas. Modular a expressão das emoções provoca uma sensação de drenagem de energia, o que pode ocasionar a exaustão emocional (Robbins et al., 2010).

Durante a discussão do caso, o professor pode, a partir das respostas dos alunos, indicar que João lidava com suas emoções utilizando algumas estratégias de regulação emocional com foco preventivo (esconder, evitar sentir ou pensar, redirecionar a atenção, preocupar-se excessivamente e reviver emoçóes negativas) e outras estratégias com foco de promoção (buscar apoio social, resolver problemas e adotar comportamentos para aceitar e validar as próprias emoções) (Leahy et al., 2013). Todavia, na maioria das vezes, João se sentia pressionado a não "demonstrar fraqueza", ou seja, evitava transparecer emoções que ele considerava negativas, tais como raiva, medo, tristeza e aversão (Silva \& Macêdo, 2021). Além disso, João não desejava influenciar negativamente outras pessoas por meio de seu comportamento. Portanto, ele modulava a expressão de suas emoções como forma de evitar desmotivar a equipe, perder a confiança conquistada entre os colegas de trabalho e preocupar sua família quanto ao futuro (Robbins et al., 2010).

A estratégia de não demonstrar suas emoções é comum entre gestores que são pressionados socialmente a serem pessoas fortes, que não demonstram fraquezas e não adoecem, uma consequência da "síndrome do trabalhador perfeito". Essa estratégia, no entanto, pode contribuir para o esgotamento emocional e o estresse entre gestores (Silva, 2009). Dessa forma, João expressava uma emoção positiva em suas palavras, postura corporal e expressões faciais. No entanto, por dentro, sentia os efeitos negativos das emoções, tais como raiva, tristeza, medo e repulsa. Com o tempo, essa dissonância emocional provocou irritação, tensão e perda do autocontrole emocional diante de situações estressantes. Além disso, a dissonância emocional causou problemas relacionados à falta de paciência e à negligência de necessidades de sua esposa e de seu filho (Robbins et al., 2010). 
Essas reflexões teóricas podem ser realizadas pelo professor durante ou após a discussão da questão com os alunos. Para balizar as reflexões, o professor também pode utilizar o Quadro 2, que apresenta situações do caso e possíveis causas da dissonância emocional de João.

Quadro 2: Situações do caso e possíveis causas de dissonância emocional

\begin{tabular}{|c|c|}
\hline $\begin{array}{l}\text { Situações do Caso em que } \\
\text { ocorreram dissonância } \\
\text { emocional }\end{array}$ & $\begin{array}{l}\text { Possíveis causas da } \\
\text { Dissonância Emocional }\end{array}$ \\
\hline $\begin{array}{l}\text { Quando ficava triste, João } \\
\text { relatava que a energia fugia } \\
\text { de seu corpo. No entanto, ele } \\
\text { esboçava um sorriso, } \\
\text { transmitia calma e confiança } \\
\text { aos seus colegas e acreditava } \\
\text { que tudo iria se resolver. }\end{array}$ & $\begin{array}{l}\text { João não queria desmotivar sua } \\
\text { equipe. Ele também não queria } \\
\text { demonstrar seus sentimentos, } \\
\text { pois acreditava que isso era um } \\
\text { sinal de fraqueza do gestor. }\end{array}$ \\
\hline $\begin{array}{l}\text { Quando João sentia raiva e } \\
\text { perdia o controle, ele } \\
\text { rapidamente se recompunha, } \\
\text { desculpava-se, dizia que tudo } \\
\text { seria resolvido e ninguém } \\
\text { precisaria se preocupar. }\end{array}$ & $\begin{array}{l}\text { João se sente responsável por } \\
\text { demonstrar confiança e por } \\
\text { resolver os problemas causados } \\
\text { pela alta administração da } \\
\text { empresa. Acredita que } \\
\text { demonstrar raiva é sinal de } \\
\text { fraqueza. }\end{array}$ \\
\hline $\begin{array}{l}\text { Quando João sentiu aversão à } \\
\text { decisão da empresa, ele } \\
\text { buscou recursos para se } \\
\text { acalmar e demonstrou uma } \\
\text { aparência mais calma e } \\
\text { equilibrada. }\end{array}$ & $\begin{array}{l}\text { João não queria desmotivar } \\
\text { seus colegas e também não } \\
\text { queria demonstrar fraqueza. }\end{array}$ \\
\hline $\begin{array}{l}\text { Quando João chegava ao } \\
\text { trabalho, a sua repulsa se } \\
\text { manifestava em seu corpo } \\
\text { através de dores de estômago, } \\
\text { náuseas e enjoos. Ele se } \\
\text { escondia para que seus } \\
\text { colegas nâo presenciassem } \\
\text { aquilo. }\end{array}$ & $\begin{array}{l}\text { João nẫo queria demonstrar } \\
\text { fraqueza. }\end{array}$ \\
\hline $\begin{array}{l}\text { João tinha medo do futuro e } \\
\text { não deixava seus colegas de } \\
\text { trabalho perceberem. }\end{array}$ & $\begin{array}{l}\text { João esperava que as equipes se } \\
\text { mantivessem positivas quanto } \\
\text { ao futuro e não queria que } \\
\text { perdessem a confiança nele. }\end{array}$ \\
\hline $\begin{array}{l}\text { João tinha medo do futuro e } \\
\text { não queria que sua família } \\
\text { percebesse. }\end{array}$ & $\begin{array}{l}\text { João não queria que sua família } \\
\text { se preocupasse com o futuro, } \\
\text { nem com o sustento da casa. }\end{array}$ \\
\hline
\end{tabular}

Fonte: autores, 2021.

O Quadro 2 revela as implicações da prática gerencial no contexto público quando a dissonância emocional é utilizada pelo gerente como recurso para não impactar no desempenho da equipe. Ao apresentar o Quadro 2 aos estudantes, o professor pode levá-los a refletir sobre a relação entre o adoecimento do gerente e a dissonância emocional, além de associar esse processo silencioso vivido por ele a uma possível "síndrome do trabalhador perfeito", cujos efeitos podem impactar na sua saúde e no seu bem-estar.

Com base nessas informações, o professor pode sugerir uma discussão sobre até que ponto a responsabilidade atribuída ao gerente de favorecer um ambiente emocional positivo para sua equipe - a partir da administração de conflitos, da valorização do grupo e da adoção de estratégias que evitem a influência negativa do contexto social e político mais amplo no desempenho dessa última - possui um custo emocional para ele, que pode comprometer o seu trabalho. A discussão sobre inteligência emocional da equipe é desenvolvida por Druskat e Wolff (2019) e pode ser mais uma referência utilizada pelo professor na reflexão do caso. 
A última questão do caso caracteriza o dilema vivenciado por João: ser ou não ser - eis a gestão. A pergunta objetiva levar os alunos a assumirem o papel de protagonista e tomarem uma decisão: continuar ou não no cargo de gestor. A seguir, apresentamos reflexões para os dois posicionamentos que podem auxiliar o professor durante a discussão com os alunos.

\section{OpÇÃo A: Jỗo deVE CONTINUAR COMO GESTOR}

Para permanecer como gestor, João precisa reequilibrar suas emoções, aceitá-las e compartilhá-las com seus colegas de trabalho, amigos e familiares. Nesse sentido, desenvolver estratégias para evitar a dissonância emocional é fundamental para a sua saúde física e mental como gestor público. Algumas estratégias que ele pode utilizar para lidar com suas emoções são: buscar apoio social em casa e no trabalho, buscar ajuda profissional, praticar exercícios físicos, alimentar-se melhor e praticar mindfulness ou outras estratégias que o auxiliem a lidar melhor com o estresse (Leahy et al., 2013). Antes de tomar a decisão, João precisa conversar com sua família e compreender que tempo, conflitos e família compõem a vida do gerente e precisam ser tratados de forma integrada, complexa e multidimensional, como aborda Silva (2009). Por fim, João deve desenvolver a sua consciência emocional, por meio da reflexão sobre as experiências em sua prática gerencial (Goleman, 1999). Isso ajudará no processo decisório e na resolução de problemas.

\section{OpÇÃo B: Jõ̃o NÃo DEVE CONTINUAR COMO GESTOR}

Ele deve se preparar financeiramente por meio de uma conversa aberta e franca com sua esposa e filho sobre a necessidade de reduzir os gastos. Nesse sentido, é necessário realizar um planejamento financeiro doméstico, considerando os gastos essenciais na opinião de todos os membros da família, no intuito de que haja colaboração com a decisão de levar uma vida mais simples. Os motivos para solicitar a exoneração de João estão vinculados à necessidade de melhorar a gestão das emoções e minimizar o impacto da dissonância emocional na saúde e no bem-estar.

Mesmo solicitando a sua exoneração da função, João pode manter e fortalecer sua rede de relacionamentos, o que possivelmente lhe proporcionará boas oportunidades de trabalho no futuro. Portanto, ele deve preparar a equipe para sua saída do cargo gerencial e dialogar com seus superiores, no intuito de que a transição ocorra de forma a causar o mínimo de danos a todos os envolvidos e a manter a sua rede de relacionamentos (Robbins et al., 2010).

Uma estratégia adotada por João para melhorar a sua saúde e bem-estar é a busca de ajuda profissional, o que pode o auxiliar a desenvolver sua consciência emocional (Goleman, 1999). Isso envolve perceber suas emoções e agir de acordo com elas. Além da consciência emocional, João precisa adotar estratégias saudáveis para lidar com suas emoções. Por fim, ele deve fortalecer os laços familiares para que possa equilibrar o tempo, os conflitos, a família e o trabalho (Leahy et al., 2013; Silva, 2009). Durante a discussão do caso, outros aspectos podem ser indicados pelos alunos como argumento para o posicionamento defendido. O professor deve analisar se eles são coerentes com o contexto e as experiências vivenciadas pelo gestor público em sua prática gerencial. 